\title{
Assessing land transformation and associated degradation of the west part of Ganga River Basin using forest cover land use mapping and residual trend analysis
}

\author{
Shafique MATIN*, Sujit GHOSH, Mukunda D BEHERA \\ Centre for Oceans, Rivers, Atmosphere and Land Sciences, Indian Institute of Technology Kharagpur, Kharagpur 721302, India
}

\begin{abstract}
The west part of Ganga River Basin (WGRB) has experienced continuous land transformation since the Indus Valley Civilisation shifted from the Indus basin to the Ganga basin. Particularly in the last few decades the land transformation has increased many-folds due to the changing climate and rapid increase in population. In this paper, we assessed land transformation and associated degradation in the WGRB based on the forest cover land use (FCLU) mapping and residual trend analysis (RTA). The FCLU maps for 1975 and 2010 were generated using 216 Landsat satellite images and validated using 1509 ground points. We mapped 29 forest and 18 non-forest types and estimated a total loss of $5571 \mathrm{~km}^{2}$ forest cover and expansion in settlement areas $\left(5396 \mathrm{~km}^{2}\right)$. Other major changes mapped include a decrease in wetlands and water bodies, while an increase in agriculture and barren lands with an overall mapping accuracy of $85.3 \%$ (kappa, 0.82) and 88.43\% (kappa, 0.84) for 1975 and 2010, respectively. We also performed the RTA analysis using GIMMS-NDVI3g to identify areas of significant negative vegetative photosynthetic change as an indicator for land degradation. All the RTA models showed monotonic nature of the residual trends and resulted as moderately positive but highly significant $(P<0.001)$. Land degradation in the form of barren land accompanied by a decline in vegetation quality and coverage was found prominent in the basin with a possibility of an accelerated rate of land degradation in future due to the rapid loss of permanent forest cover.
\end{abstract}

Keywords: land degradation; remote sensing; NDVI; GIMMS; Ganga River Basin

Citation: Shafique MATIN, Sujit GHOSH, Mukunda D BEHERA. 2019. Assessing land transformation and associated degradation of the west part of Ganga River Basin using forest cover land use mapping and residual trend analysis. Journal of Arid Land, 11(1): 29-42. https://doi.org/10.1007/s40333-018-0106-y

\section{Introduction}

The Indian Green Revolution resulted in a massive transformation of the vegetated lands into heavily irrigated agricultural land and enabled India to be self-sufficient in food production but prompted environmental issues including green cover loss and land degradation (Shiva 1991; Gupta et al., 2003). Deterioration of the land quality can be prevented by timely detection of the process thereby leading to preventing measures (Higginbottom and Symeonakis, 2014). Despite the global concern on land degradation (UNCCD, 1994; Reynolds et al., 2007), Helldén and Tottrup (2008) and Fensholt et al. (2012) questioned the exactness of the problem due to the lack of proper

*Corresponding author: Shafique MATIN (E-mail: shafiquematin@gmail.com)

Received 2017-11-10; revised 2018-06-14; accepted 2018-06-22

(C) Xinjiang Institute of Ecology and Geography, Chinese Academy of Sciences, Science Press and Springer-Verlag GmbH Germany, part of Springer Nature 2019 
evidence for its magnitude and spatial extent. Land transformations can be understood by evaluating land conversion and land modification (Bajocco et al., 2012). Land conversion refers to the complete replacement of one land cover type with another, while land modification indicates indirect changes that affect the character of the land cover without changing its attributes (Leemans and Zuidema, 1995). A forest cover land use (FCLU) mapping provides information on the natural and managed lands and offers a base to understand geomorphological changes over-time (Symeonakis et al., 2007; Behera et al., 2014). A managed land maintained for commercial uses is more vulnerable to degradation compared to a natural forested land (Lamb, 2011). An inventory of land cover changes thus helps to understand the pattern of different degradation types. The change process is generally gradual, therefore its measurement must stick to the principles of consistency (Hill et al., 2008), that makes the geoinformatics techniques an obvious choice (Bai et al., 2008).

Land degradation is generally climate-driven or human-induced or a combination of the both (Wessels et al., 2007; Eckert et al., 2015; Sklenicka, 2016). Climate-driven land degradation includes extreme and periodic climatic variations which give rise to events like a change in the surface energy budget, frequent drought episodes and aridity change (Dregne, 1977; Mbow et al., 2015), whereas, human-induced land degradation generally occurs due to over-exploitation of natural resources, agricultural mismanagement, deforestation, mining, industrial expansion and many other factors (Evans and Geerken, 2004; Gabriels and Cornelis, 2009). An accurate measurement of the vegetation productivity in relation to the water availability in the region is a prerequisite to understand the human-induced land degradation (Zhang et al., 2017). There are few methods in practice to distinguish the role of water available in the land degradation process. For example, the negative coefficient in trend-correlation analysis between the normalised difference vegetation index (NDVI) and rainfall indicates degraded land. Another method is the rain-use efficiency (RUE) determination, which works on the assumption that a decline in RUE over-time indicates land degradation where rainfall is a major limiting factor for plant growth (Dardel et al., 2014). Residual trend analysis (RTA) examines the residuals from the NDVI and water regression model over-time to reveal the proportion of NDVI change that is not due to climatic variability (Ibrahim et al., 2015). Most of the land degradation analyses are based on vegetation index data as a proxy for net primary production (NPP), especially NDVI (Higginbottom and Symeonakis, 2014). All such methods are based on the same assumption that the deterioration is likely caused by human-induced factors if there are no other natural drivers of NPP decline in the region (Le et al., 2016).

Primary productivity largely depends on the availability of water, either in the form of rainfall (Dubey et al., 2012) or soil moisture (Kumar and Rao, 2013), which allows differentiating the effect of human activities. For extricating the effects of human-induced land degradation, RTA technique has extensively been used (Evans and Geerken, 2004; Li et al., 2016). The technique uses the model residuals from the NDVI and water regression over-time to find out the proportion of NDVI change not controlled by water. An increase or a decrease in vegetation photosynthetic capacity can be marked by a significant increase or decrease of the residuals of NDVI over time. Though the vegetation photosynthetic capacity depends on many environmental and physiological factors, the most important factor is the water availability (Wang et al., 2003).

In this paper, we attempted to assess land transformations in the west part of Ganga River Basin (WGRB) and its associated land degradation. We used the Landsat satellite images to map the zones of the FCLU change for 35 years and RTA technique to assess human-induced land degradation. Spatial and temporal distribution of the degraded lands and their response against water unavailability were produced with visual images of land degradation for few of the severely degraded zones.

\section{Materials and methods}

\subsection{Study area}

This study was carried out in a hydrological unit of $8 \times 10^{5} \mathrm{~km}^{2}$ in the west part of Ganga River 
Basin (WGRB; Fig. 1). WGRB has the Himalayas in the north, the Thar Desert in the west, the Aravalli hills in the south and the Sundarbans delta in the east. Apart from the snow-covered mountains in the north, the major part of the basin is low-lying at $<300 \mathrm{~m}$. The WGRB has been predominantly occupied with agricultural land and considered as the food bowl of India. The region is experiencing rapid growth in infrastructure and construction with an overly dense population of above $5 \times 10^{8}$ (Census, 2011). Intensive agricultural practice to cater the thick population growth has led to the depletion of groundwater, increase in salinity and decline in land productivity. The climate of the eastern part of the basin is subequatorial monsoon while a tropical climate prevails in the west. Monsoon circulation weakens toward the west and increases the dryness in the soil.

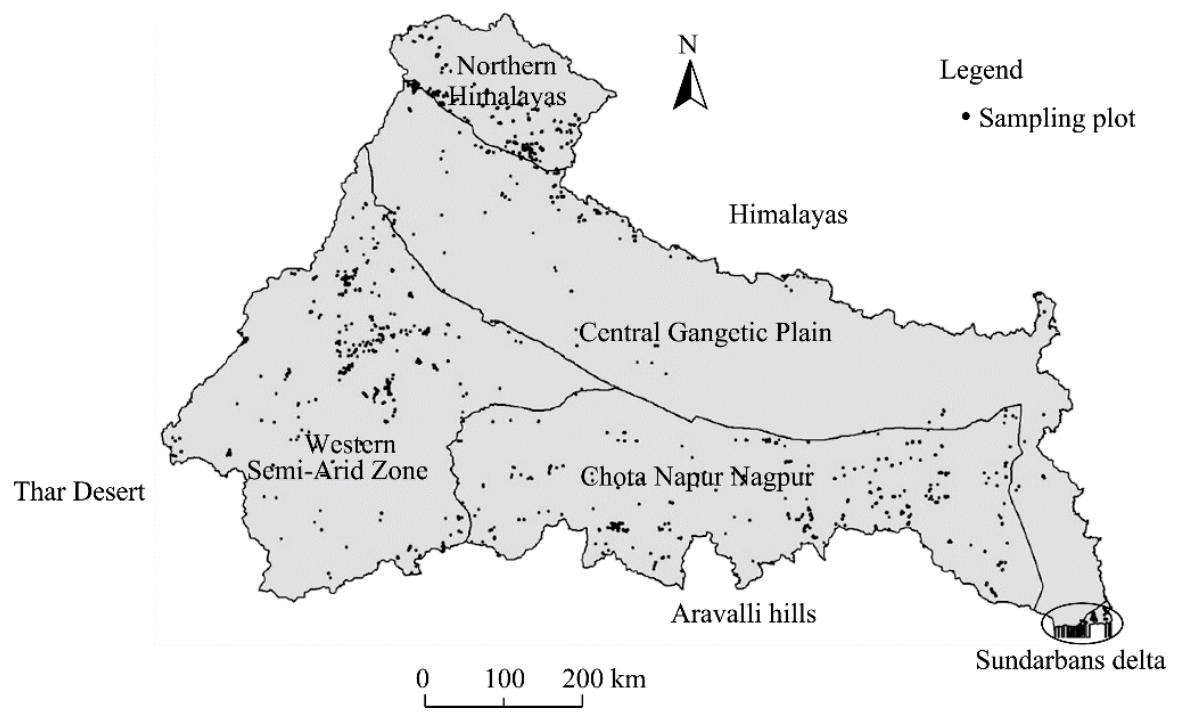

Fig. 1 Biogeographical zones and the sampling plots in the west part of Ganga River Basin (WGRB)

The western WGRB has a semi-arid climate with an annual rainfall of 500-800 mm, whereas the eastern part experiences a humid climate with an annual rainfall of 1000-2000 mm (Ali et al., 2000). The soil types in the basin are majorly sandy, loamy, clay and their combinations such as sandy loam, silty clay, and few others. According to its climatic variability, the basin can be divided into four biogeographical zones as Northern Himalayas, Central Gangetic Plain, Western SemiArid Zone and Chota Nagpur Plateau (Fig. 1).

\subsection{Data}

For forest cover and land use mapping, we acquired 114 Landsat multispectral scanner (MSS) scenes and 102 Landsat thematic mapper (TM) scenes of the years of 1975 and 2010, respectively, from the United States Geological Survey. The satellite data of pre-monsoon (March to May) and post-monsoon (October to December) seasons were acquired to map the phenological variations in different FCLU types. GIMMS-NDVI3g dataset was used in the RTA to analyse the changes in the photosynthetic capacity of different vegetation types. GIMMS-NDVI3g is a long-term NDVI data derived from the advanced very high-resolution radiometer instruments on board of the NOAA satellites. This dataset covers the period from July 1981 to December 2013 with a bi-weekly temporal coverage and 8-km spatial resolution (Xu et al., 2013). The bi-weekly data were converted to monthly aggregates using the maximum value composite method to further minimize the effects of cloud contamination (Holben, 1986). All the datasets were resampled into 8- $\mathrm{km}^{2}$ grids using the nearest-neighbour algorithm and masked to fit the study area. We acquired the global rainfall data (v3.23), available on the Climate Research Unit website (www.cru.uea.ac.uk) and soil moisture dataset from the ESA-CCI in the RTA. Rainfall data are monthly gridded $\left(0.5^{\circ}\right.$ grid $)$ rainfall estimates, calculated from daily or sub-daily data (Yan et al., 2016). Soil moisture dataset, generated by the ESA-CCI under a soil moisture project presents daily surface soil moisture in volume metric unit at a spatial resolution of $0.25^{\circ}$ (EODC, 2015). 


\subsection{Methods}

As showing in Figure 2, we firstly produced two time period FCLU maps to identify areas with significant land transformation during 1975-2010 (Step 1). Then RTA was carried out considering NDVI as a proxy to delineate human-induced land degradation (Step 2). Finally, a map of land transformation and associated land degradation was produced by combining the FCLU change map and the human-induced land degradation map with visual image-chips of Landsat satellite images (Step 3).

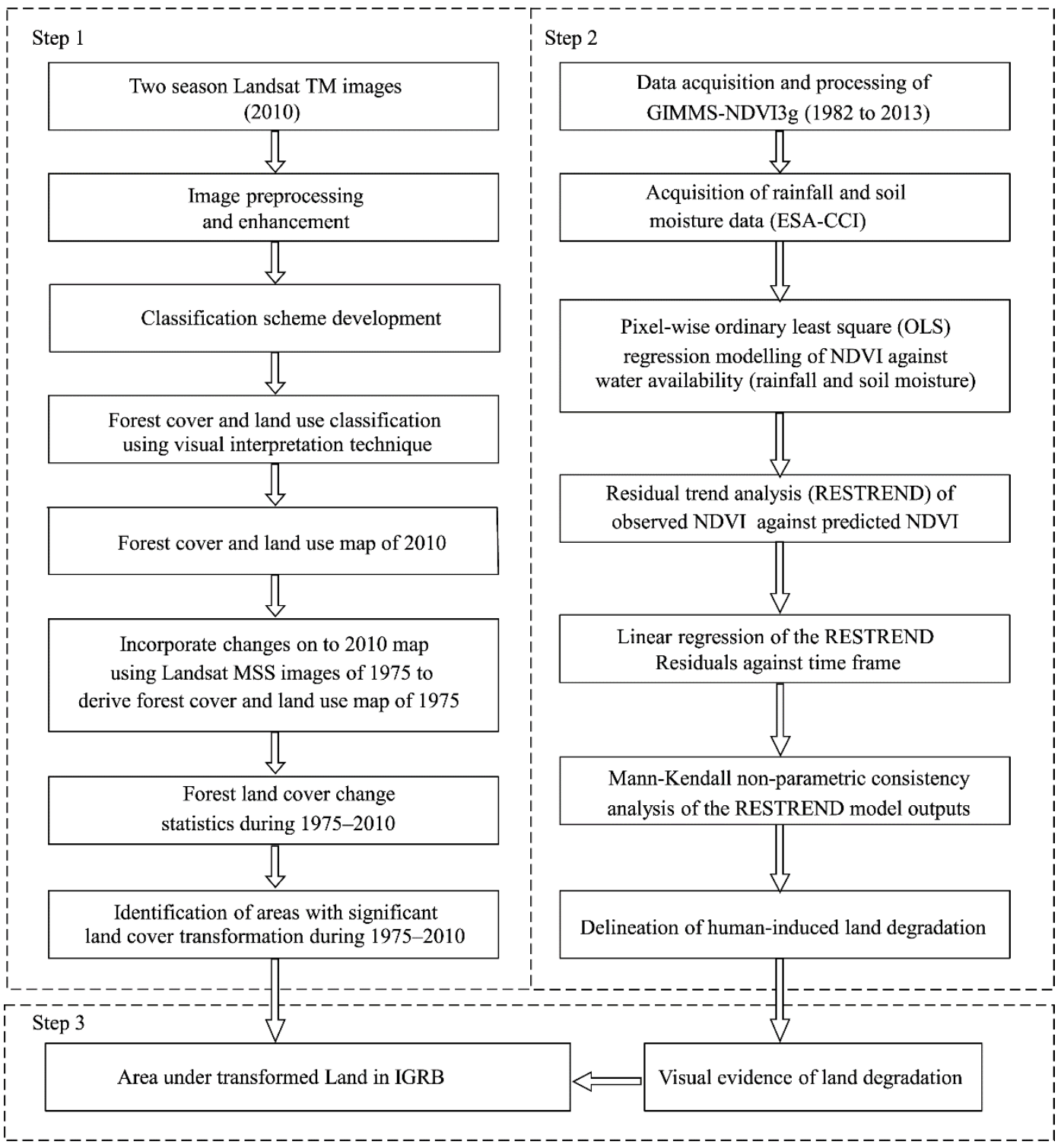

Fig. 2 Methodology paradigm adopted to assess land transformation

\subsubsection{Forest cover land use mapping}

Moderate resolution $(30 \mathrm{~m})$ images of Landsat TM sensor were used to prepare the FCLU map of 2010 at first and the 1975 FCLU map was generated by editing the 2010 shapefiles utilizing the 60 $\mathrm{m}$ Landsat MSS images in the backdrop. Visual interpretation technique was applied to classify the entire study area into 47 different types following a pre-existing classification scheme (Table 1). The scheme divides the entire study area into vegetation and non-vegetation types and further into 29 forest and 18 non-forest types. The forest types were subdivided into mixed, gregarious, locale- 
specific, degraded/successional formations and plantation. Degraded forest resulted mostly from human interferences, but also by natural succession. A class-wise comparison was carried out to estimate the changes in the area statistics during the period 1975-2010. The mapping accuracy was accessed using 1509 sample plots gathered through field sampling during the biodiversity characterization at landscape level project using a sample size of $20 \mathrm{~m} \times 20 \mathrm{~m}$ for trees, $5 \mathrm{~m} \times 5 \mathrm{~m}$ for shrubs and $1 \mathrm{~m} \times 1 \mathrm{~m}$ for herbs (Matin et al., 2012).

Table 1 Forest cover land use (FCLU) classification

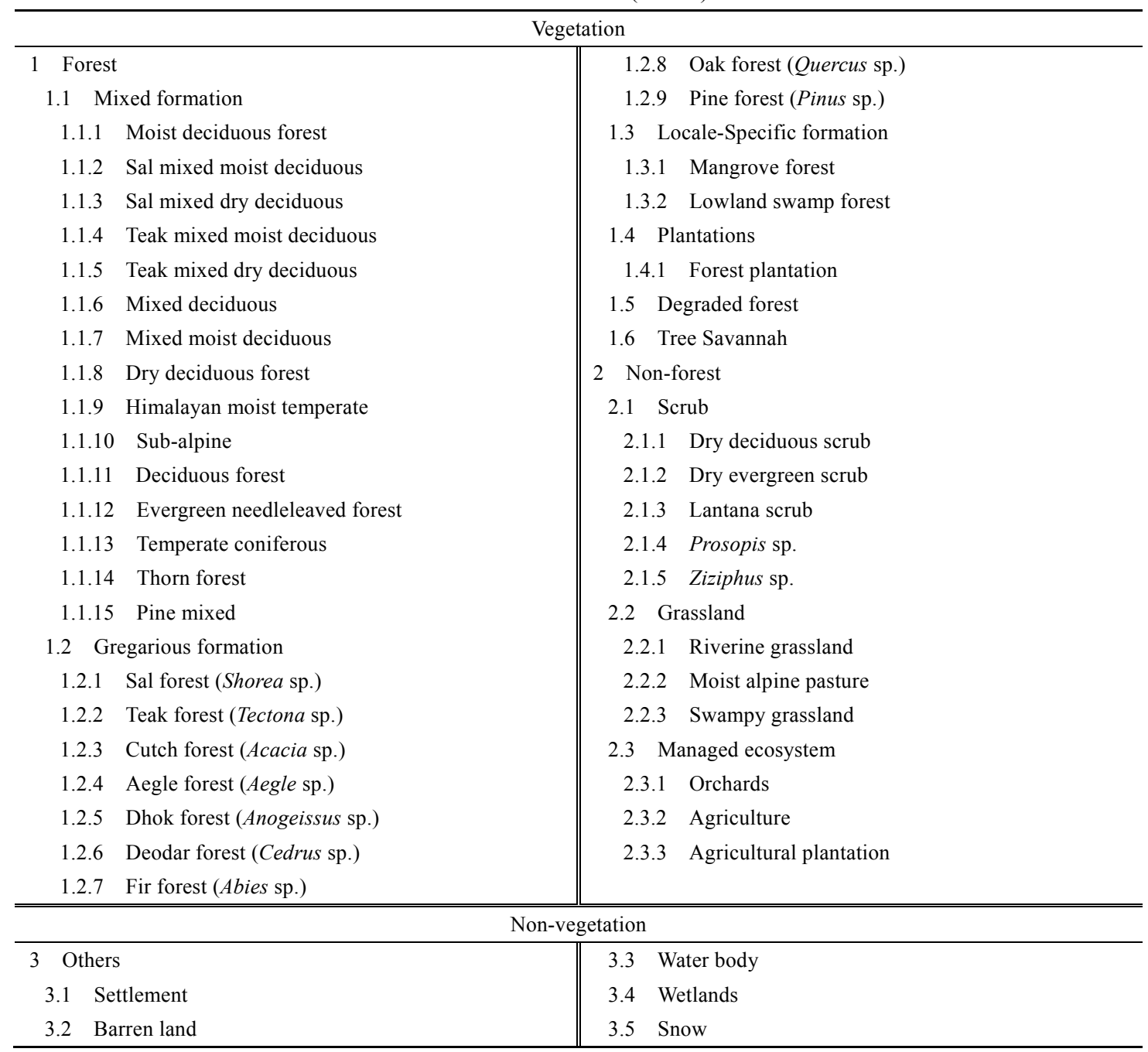

\subsubsection{Residual NDVI trend}

Statistical methods were used to evaluate the patterns of the residual NDVI trends. Ordinary least square regression model was used to examine the parameters of the linear relationship of NDVI against rainfall and soil moisture. The method measures the linear relationship (Eq. 1) between a dependent $(y)$ and independent variables $(x)$.

$$
y=b x+a+\varepsilon
$$

where $y$ is the NDVI; $x(\mathrm{~mm})$ is the rainfall; a is an intercept representing the value of $y$ when $x$ is 0 ; $\mathrm{b}$ is the slope of the relationship between $y$ and $x$; and $\varepsilon$ is the error term.

2.3.3 RTA analysis

Photosynthetic capacity of vegetation represented as NDVI was observed using the linear regression model mentioned in the previous section. The residuals between observed and predicted 
NDVI values were examined using RTA. This measurement comprises three major steps. Firstly, a pixel-based linear regression modelling between the observed NDVI against rainfall and soil moisture was carried out. Secondly, RTA residuals were analysed by calculating the difference between the observed NDVI and the predicted NDVI. Finally, a linear regression was conducted on the RTA residuals against time. These residual trends represent the changes in ecosystem productivity that was independent of water availability and indicates land degradation.

\subsubsection{Consistency measurement}

The consistency of the RTA results was validated using the Mann-Kendall non-parametric trend analysis. Mann-Kendall is a test to check whether the values of a variable are increasing or decreasing with time (Helsel and Hirsch, 2002). The output results in a range between -1 and 1 , where -1 indicates a consistent decreasing trends and 1 indicates consistent increasing trends whereas a 0 indicates no trend at all (Ibrahim et al., 2015).

\subsection{Evidence of land degradation}

Satellite images of Landsat MSS and Landsat TM were perused to visualise the effects of land degradation in 1975 and 2010. Image chips were prepared from the areas where degradation was primarily caused by factors other than climate based on the RTA analysis.

\section{Results}

\subsection{Land transformation during 1975-2010}

The total area under different vegetation cover (including forest) in the region estimated in both the maps was $19.48 \%$ and $19.03 \%$ for 1975 and 2010, respectively (Table 2). We mapped 29 forest types covering an area of $1.28 \times 10^{5} \mathrm{~km}^{2}$ in 1975 map and $1.20 \times 10^{5} \mathrm{~km}^{2}$ in 2010 map (Fig. 3). The deciduous forest was not only mapped as the major forest cover in the basin but also showed the highest forest loss $\left(4397 \mathrm{~km}^{2}\right)$ during 1975 and 2010. An increase in the forest plantation (1557 $\left.\mathrm{km}^{2}\right)$ and degraded forest cover $\left(580 \mathrm{~km}^{2}\right)$ was mapped in the Northern Terai. Agricultural land of the Central Gangetic Plain was also found encompassed by orchard plantation and invasion of Prosopis scrub in 2010 map. In non-vegetation cover types, the settlement was mapped showing the highest increase of $5396 \mathrm{~km}^{2}$, followed by barren $\left(212.86 \mathrm{~km}^{2}\right)$, while water body and wetland cover types were also observed to be reduced over time (Table 2).

Table 2 FCLU mapping of 1975 and 2010

\begin{tabular}{|c|c|c|c|c|c|c|c|}
\hline \multirow{2}{*}{ Class } & \multicolumn{3}{|c|}{ Vegetation cover $\left(\mathrm{km}^{2}\right)$} & \multirow{2}{*}{ Class } & \multicolumn{3}{|c|}{ Vegetation cover $\left(\mathrm{km}^{2}\right)$} \\
\hline & 1975 & 2010 & Change & & 1975 & 2010 & Change \\
\hline Agriculture & $573,055.15$ & $575,727.90$ & 2672.70 & Scrubland (6 types) & $30,984.81$ & $30,824.9$ & -159.94 \\
\hline Settlement & $11,371.72$ & $16,767.98$ & 5396.30 & Grassland (4 types) & 7195.28 & 7040.18 & -155.10 \\
\hline Forest (27 types) & $104,531.46$ & $98,978.21$ & -5553.30 & Barren land & $14,182.40$ & $14,395.30$ & 212.87 \\
\hline Mangrove & 866.08 & 847.58 & -18.50 & Water body & $14,375.59$ & $12,948.20$ & -1427.38 \\
\hline Forest plantation & $12,402.18$ & $13,959.69$ & 1557.50 & Wetlands & $14,967.82$ & $13,448.50$ & -1519.29 \\
\hline Orchards & 8.97 & 744.59 & 735.62 & Snow & $16,778.56$ & $15,037.00$ & -1741.54 \\
\hline Agricultural plantation & 3.25 & 3.26 & 0.01 & & & & \\
\hline
\end{tabular}

Note: Types merged for easy comparison.

A total of 1509 sample points were plotted against the FCLU maps, which resulted in an overall accuracy of $85.30 \%$ and $88.43 \%$ for 1975 and 2010 , respectively. Similarly, to check the agreement between the classified types and reference data, a non-parametric Kappa coefficient was calculated as 0.84 for 2010 and 0.82 for 1975 . 


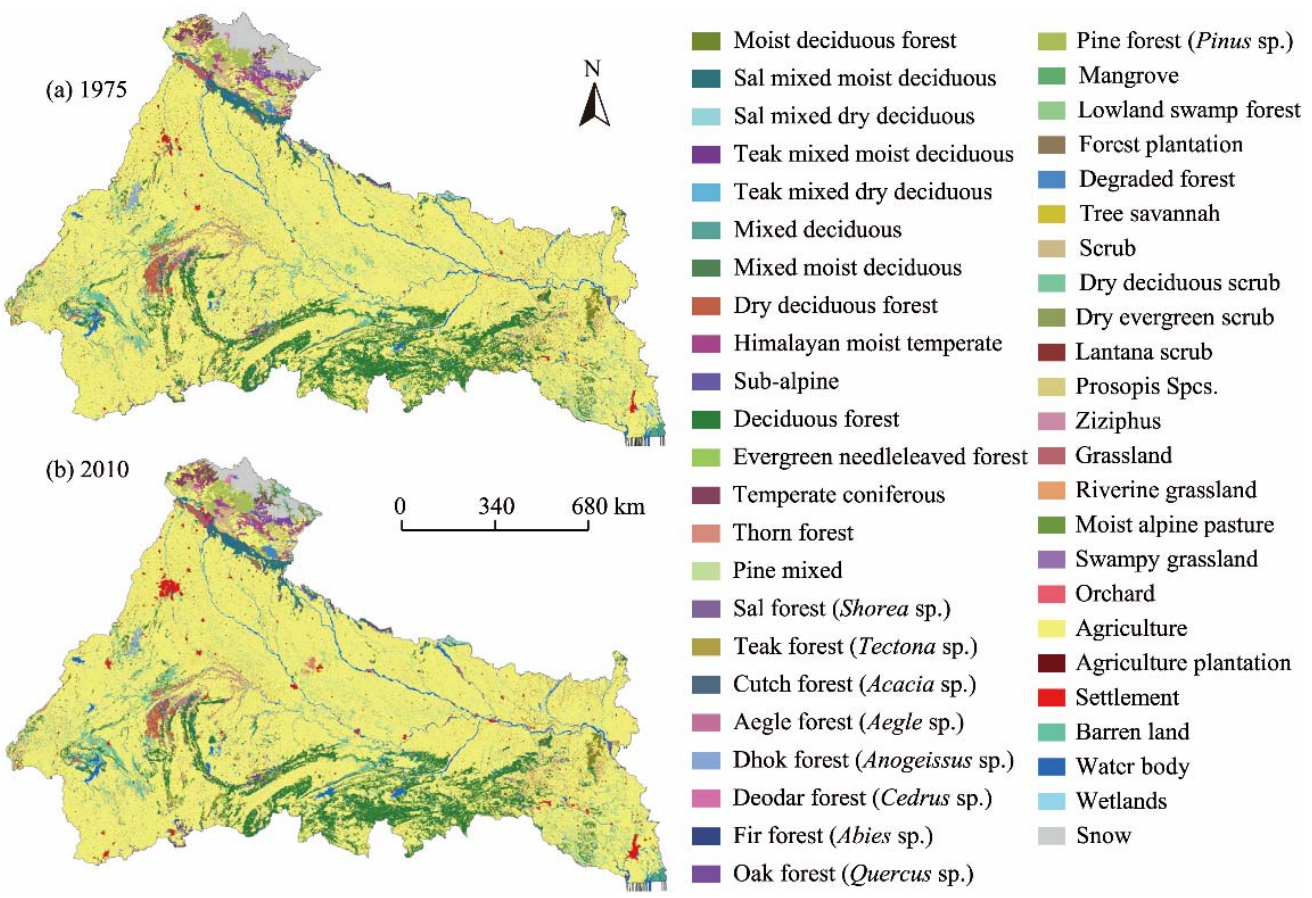

Fig. 3 Forest cover and land use map of the WGRB for 1975 (a) and 2010 (b)

\subsection{NDVI change and residual patterns of rainfall and soil moisture}

A strong increase of NDVI was observed in the Western Semi-Arid Zone but not in the Central Gangetic Plain where soil remains relatively humid (Fig. 4a). Similarly, the NDVI value increases in response to higher rainfall in the Central Gangetic Plain and Chota Nagpur Plateau (Fig. 4b). Figure $4 \mathrm{c}$ shows that soil moisture variability had no effect on the central Gangetic Plain, whereas the Western Semi-Arid Zone suffered badly due to the low soil moisture. A similar NDVI intercept in absence of rainfall can be seen in the Figure $4 \mathrm{~d}$.
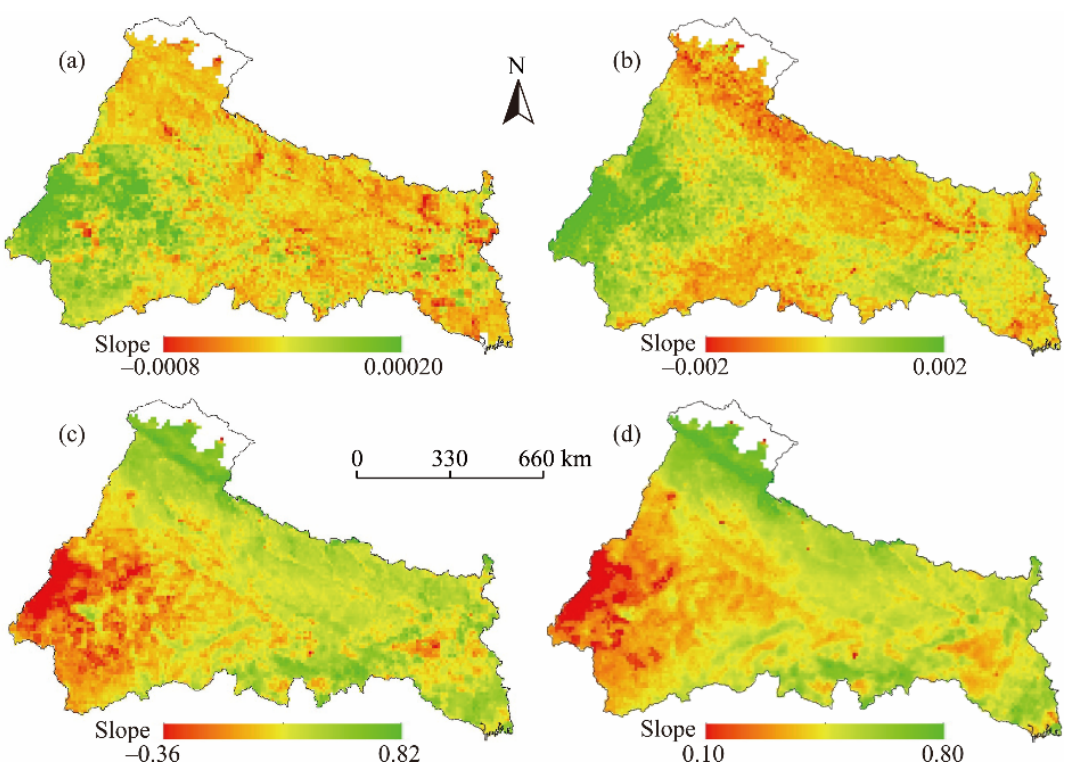

Fig. 4 Showing linear regression results as the spatial pattern of the slope for NDVI against (a) soil moisture and (b) rainfall, and intercept of the NDVI when (c) soil moisture and (d) rainfall are zero. Snow cover was masked to avoid modelling distractions. 
Full positive and negative residual trends for soil moisture can be seen in Figure 5a. This result was filtered to show only areas with negative trends at $95 \%$ confidence level and considered as significantly degraded (Fig. 5b). Similarly, Figure 5c is showing the full positive and negative rainfall residuals and Figure $5 \mathrm{~d}$ is showing the areas with significant negative trends at $95 \%$ confidence level. Severe land degradation was not only observed in the Western Semi-Arid Zone but also in the humid zones of northern Gangetic plains. Effect of industrial expansion and industrialization on land degradation can also be seen in the Chota Nagpur region (Fig. 5). A closer inspection of the distribution of positive and negative trends of the NDVI residuals from two models shows that the NDVI based RTA has a negative trend for both of them (Fig. 6). The adjusted RTA NDVI residual shows a predominantly negative trend for both soil moisture and rainfall.

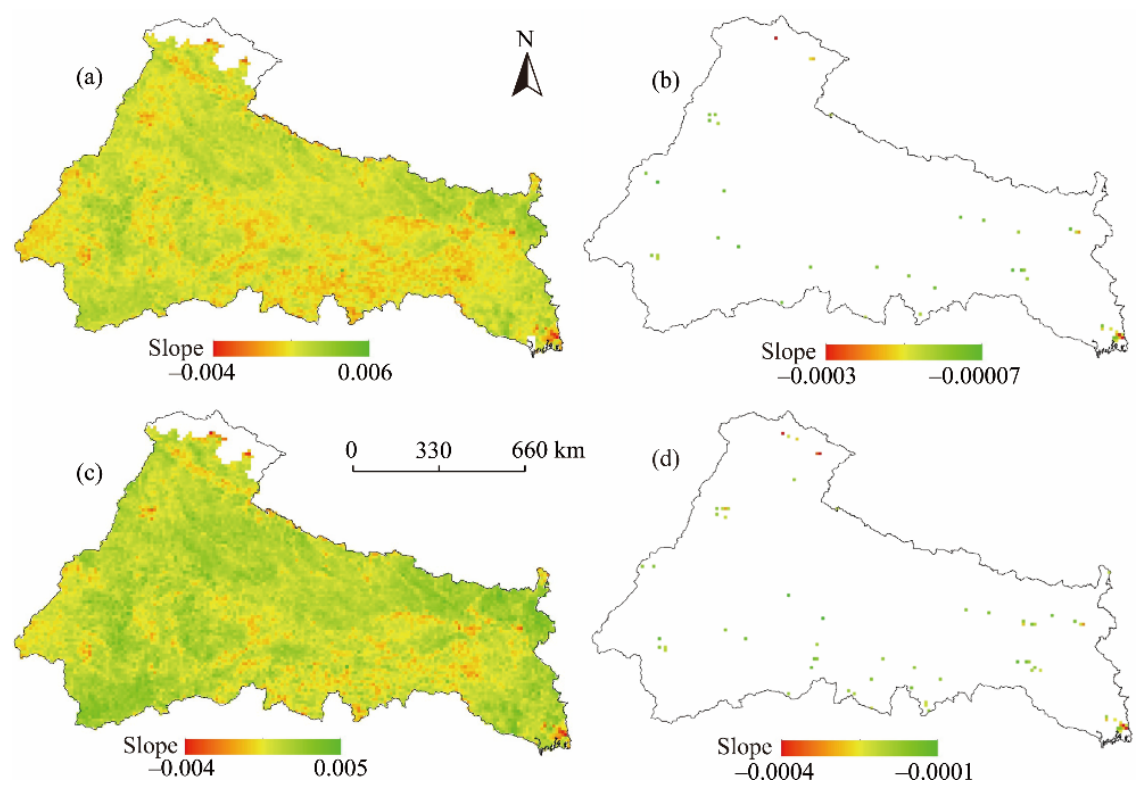

Fig. 5 Spatial distribution slope of the regression residuals of NDVI against time, for soil moisture (a) and its significant negative trends at 95\% confidence level (b); slope for rainfall(c) and its significant negative trends at 95\% confidence level (d). Negative values indicate land degradation in the study area between 1982 and 2013.

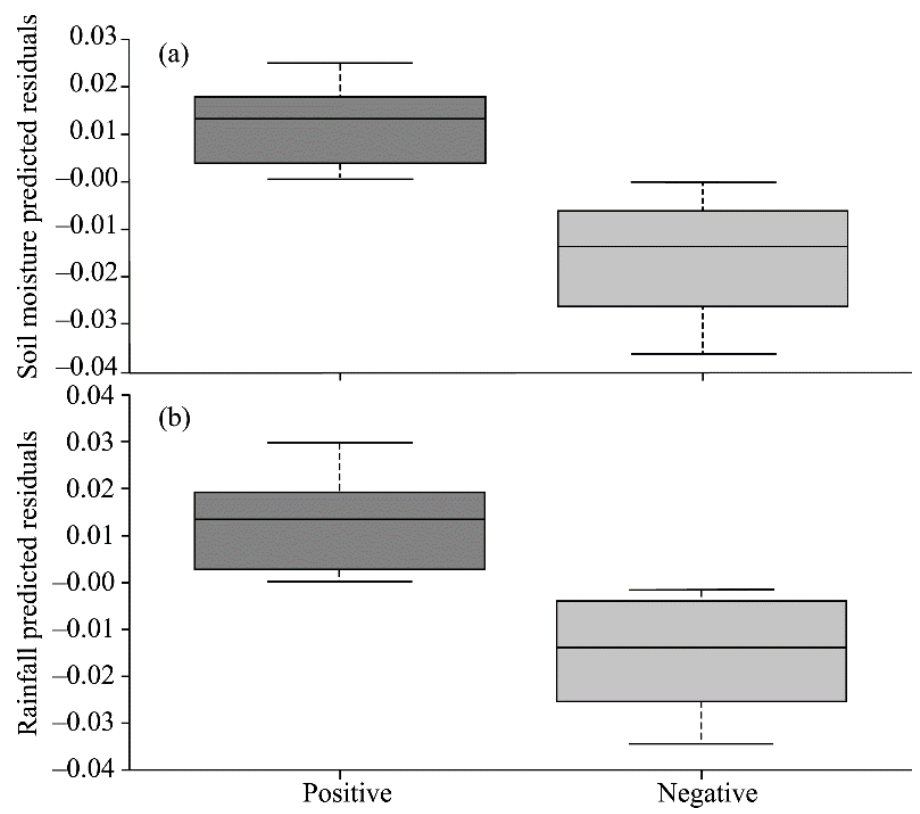

Fig. 6 Adjusted residual trend analysis (RTA) trends of NDVI residuals for (a) soil moisture and (b) rainfall 


\subsection{RTA temporal variation of annual NDVI residuals}

Rainfall adjusted RTA showed a negative trend from 1982 to 1993, although the soil moisture residuals differ for the year 1989 and showed a minor positive trend for 1990. Later from 1994 to 2013 all the years were showing positive residual trends with only two years with negative residual trends of insignificant magnitude. The effects of drought during the 1970s to the late 1990s were apparent in the results with negative trends of vegetation greenness up to the early 1990s (Fig. 7).

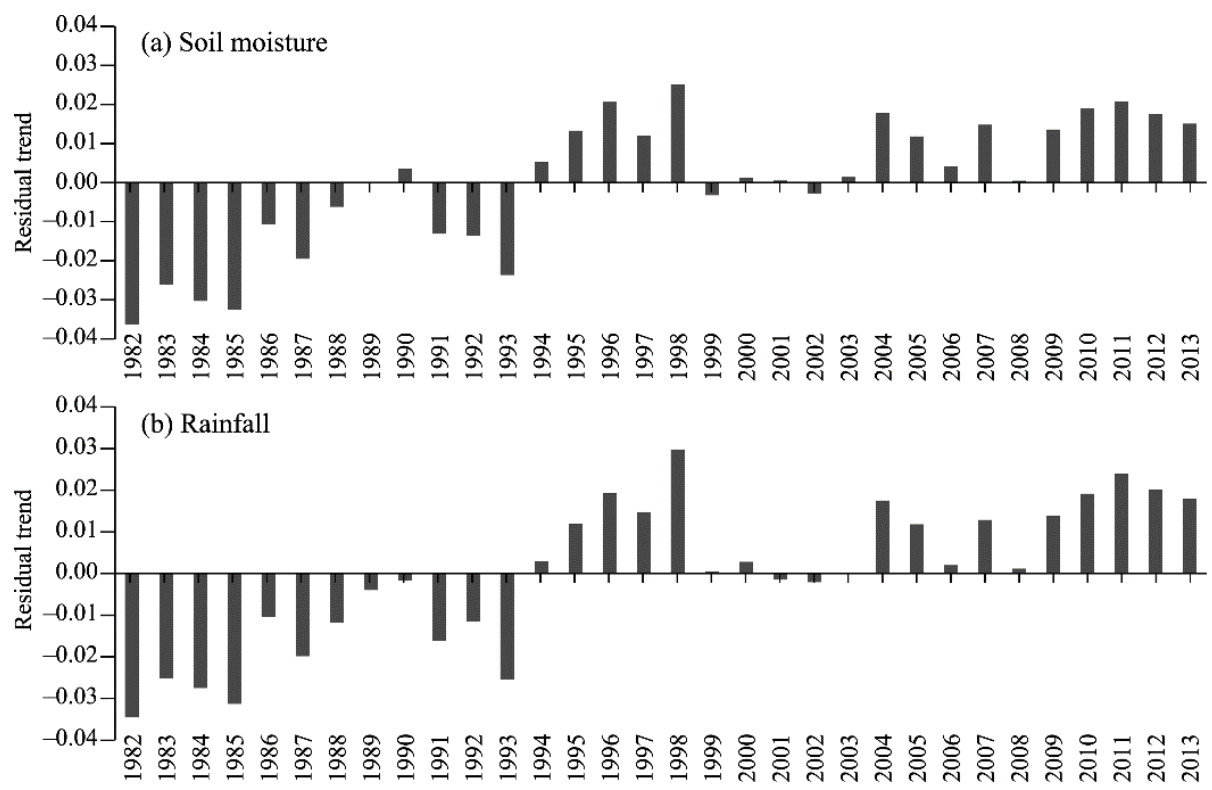

Fig. 7 Annual mean RTA NDVI residuals for 1982 to 2013. Values were adjusted for (a) soil moisture and (b) rainfall for more robust and consistent identification of years showing land degradation.

\subsection{Mann-Kendall trend consistency analysis}

Table 3 shows that the overall trend of the RTA in the WGRB is positive but highly significant $(P<0.01)$ for all of the RTA models. It also showed that the trend of the adjusted NDVI residuals for both soil moisture and rainfall are significantly increasing in some areas.

Table 3 Mann-Kendall trend analysis

\begin{tabular}{lcc}
\hline Residual trend analysis (RTA) & Coefficient Tau $(\tau)$ & $P$ \\
\hline Rainfall-NDVI (all years) & 0.609 & $<0.001$ \\
Soil moisture-NDVI (all years) & 0.577 & $<0.001$ \\
\hline
\end{tabular}

\subsection{Land degradation in major land cover types}

Agricultural land showed the largest area $\left(1664 \mathrm{~km}^{2}\right)$ under significant land degradation, followed by settlement and forest lands with areas of 704 and $576 \mathrm{~km}^{2}$, respectively (Table 4). Areas near to industrial townships or mining sites were also found susceptible to land degradation, regardless of the land cover types. Lands under dense forest cover found relatively less degraded $\left(192 \mathrm{~km}^{2}\right)$ compared to scrub land $\left(384 \mathrm{~km}^{2}\right)$ and other vegetation cover types.

\section{Discussion}

\subsection{FCLU change and land degradation}

Forest cover loss and the changes of the other land cover types were assessed for the period 19752010 to understand the land transformation and associated land degradation in the WGRB. Out of the 47 FCLU types, 26 were found showing increases and 21 with decreases in the total area during the period. 
Table 4 FCLU classes merged into 8 broad types to analyse the impact of land degradation in eight different land units

\begin{tabular}{lcc}
\hline Land use type & Number of pixels & Area $\left(\mathrm{km}^{2}\right)$ \\
\hline Agriculture & 26 & 1664 \\
Settlement & 11 & 704 \\
Forest (27 types) & 9 & 576 \\
Grassland (4 types) & 2 & 128 \\
Mangrove & 1 & 64 \\
Forest plantation & 3 & 192 \\
Scrubland (6 types) & 6 & 384 \\
Barren land & 2 & 128 \\
\hline
\end{tabular}

Note: 1 pixel is $8 \mathrm{~km}^{2}$.

A massive decrease (34\%) in the dry deciduous forest was observed that can be attributed to the increasing agricultural practice and urbanization in the region. The forest survey of India also reported a total forest cover loss of about $3 \times 10^{5} \mathrm{hm}^{2}$ in Jharkhand during 1977-2015. Similarly, an increase of about $50 \%$ in the settlement area in 2010 FCLU map signifies the exerting pressure on barren land and scrub land. Behera et al. (2014) reported an increase of about $45 \%$ in settlement for the same period and location but did not explain the causative factors. An increase of $12 \%$ in the forest plantation class in 2010 map was a result of the forest gap-filling exercise by the state forest department. Other major declines occurred in water bodies and wetlands by $10 \%$ and $12 \%$, respectively. Behera et al. (2012) also reported a rapid shrinkage of water bodies and wetlands in Upper Ganges mostly due to the expansion of the agricultural area and resulted in a formation of dry bare soil. A bare soil is more vulnerable to degradation due to erosion forces and loss of moisture compared to a covered vegetated soil (Gupta et al., 2011). Expansion in the agricultural infrastructure has also changed the physical and chemical properties of the soil, resulting in a decline of the soil productivity, which in-turn leads to land degradation. Due to the rapidly increasing population and the demand of high crop yield, the existing farmlands in the WGRB are being fertilized and intensified to multiple crop rotations resulting in soil salinization and biodiversity decline (NBSS and LUP, 2005). A reduction in soil has made soils more vulnerable to degradation (Dubey et al., 2012). Other critical issues observed in the WGRB are soil sealing due to urbanization, industrialization and mining that was found contributing majorly to the land degradation process (Matin and Behera, 2016).

\subsection{Residual change and its consistency}

Vegetation growth was found influenced majorly by the change in water availability in the region following the general rule that NDVI approaches zero when water availability is also zero (Ibrahim et al., 2015). Therefore, areas with negative NDVI intercept with high rainfall represent the zones of human-induced land degradation. A change in plant productivity not caused by the variation in water availability can be measured by quantifying the residual trend patterns. The residual of the linear regression between NDVI and water availability thus identified the portion not explained by either of the variables (Ibrahim et al., 2015). In the WGRB, the RTA presented areas with the negative trend as degraded and areas with the positive trend as improved or at least not degraded land. The average temporal trend of annual residual for the period 1982-2013 showed strong negative residuals of vegetation productivity less than the overall average for the period 19821993. A negative trend of vegetation greenness up to the early 1990s (Fig. 7) is similar to what was reported by Gupta et al. (2011), which can be linked to the severe drought during the early 1970s to late 1990 s.

Mann-Kendall coefficient Tau $(\tau)$ showed a very good consistency for all the RTA models but with certain limitation. For example, RTA does not give a reliable result at the end of the timeseries as compared to the middle year trends and shows the incapability to identify areas under land degradation with high rainfall variability or past severe droughts. 


\subsection{Land cover change and degradation}

Severely degraded regions outlined on the FCLU change map and on the RTA map were joined and displayed in Figure 8a. Image-chips prepared from Landsat satellite (MSS and TM sensors) was discovered capable in demonstrating visual confirmation of land degradation in spite of its coarse spatial resolution (Figs. 8b-d). In Figure 8b, image-chips confirmed the conversion of scrub and agriculture land into white patches of sodic soil around the canals. A newly built network of canals can be seen in 2010 image-chip, which quickened the water leaching and soil salinization in many
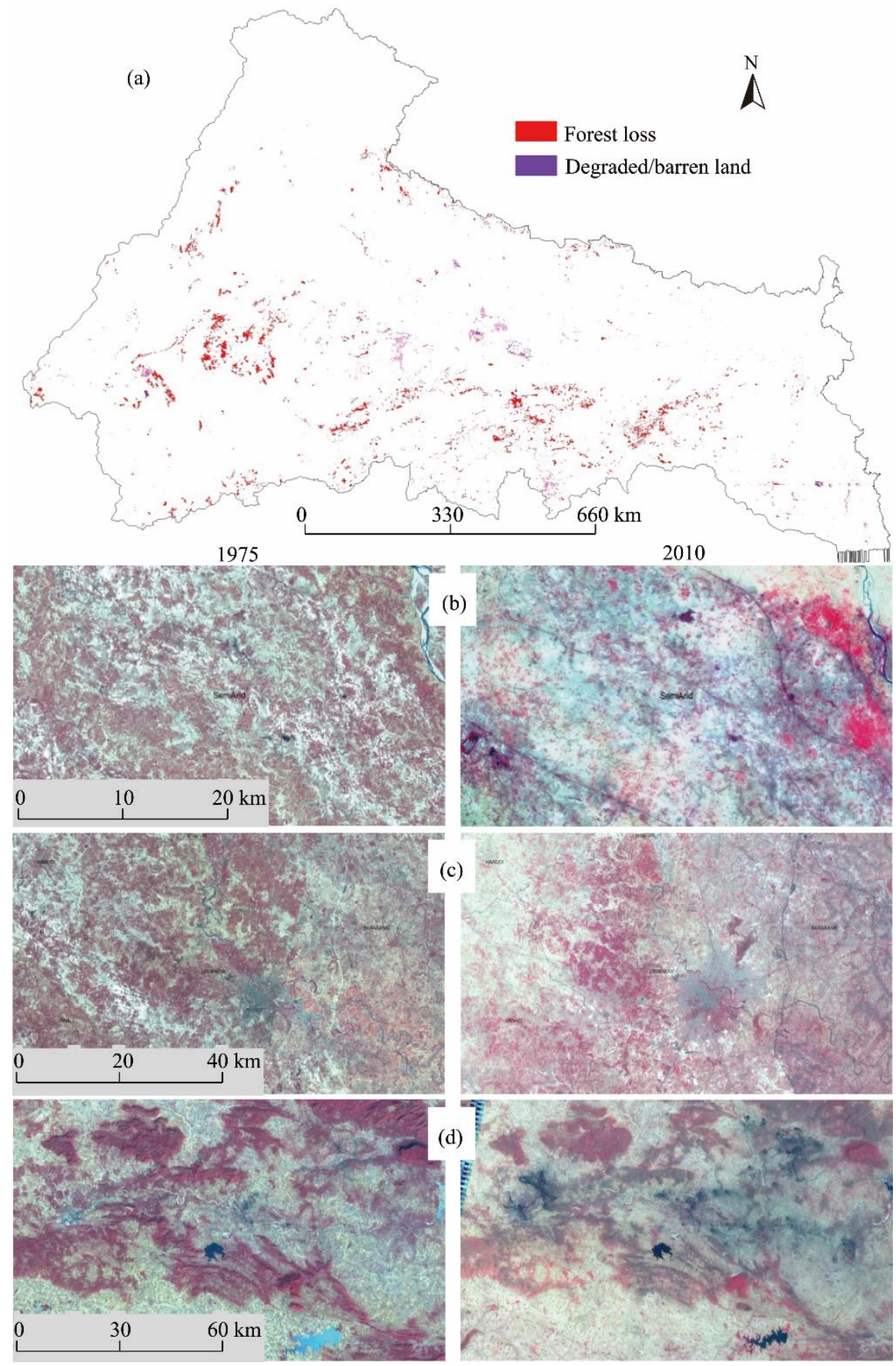

Fig. 8 Showing (a) the combined map of degraded areas delineated on the FCLU and RTA maps, (b) image-chips for conversion of scrub and agriculture land into white patches of sodic soil, (c) expansion in settlement areas and the introduction of agroforestry, and (d) cascading effects of surface mining and rapid industrialization. 
parts of the region. An enormous development in urban settlement and expansion of agroforestry can also be found in Figure 8c. In Figure 8d, cascading impacts of surface mining and industrialization can be seen particularly in the south-eastern part of the WGRB. This is a typical example of human-induced land degradation that has contributed to a great extent in the formation of degraded land in many developing nations (Bajocco et al., 2012).

\section{Conclusions}

The study presented the distribution of degraded lands in the WGRB and satellite-based evidence for some of the severely degraded regions. Both FCLU maps and the RTA found capable in assessing areas under different land degradation types where latter used the vegetative photosynthetic change to delineate human-induced land degradation. We observed a massive transformation of vegetated land into barren lands, an expansion in agriculture and settlement areas, a loss of permanent forest cover, and a significant negative vegetative photosynthetic change. Land degradation in the form of barren land formation accompanied by a decline in vegetation quality and coverage was found prominent in the lower part of the basin especially in the states like Madhya Pradesh, Rajasthan, Jharkhand and West Bengal. We argue on the possibility of an accelerated rate of land degradation in the future due to the rapid loss of permanent forest cover. All the RTA models showed monotonic nature of the residual trends and resulted as moderately positive but highly significant that facilitated the human contribution of land degradation in areas adjacent to canals, mines, and major industrial establishments. Results of this study may serve as baseline information to assess land degradation in the WGRB with the possibility to incorporate better resolution data for more refined results.

\section{References}

Ali M, Joshi P K, Pande S, et al. 2000. Legumes in the Indo-Gangetic Plain of India. In: Johansen C, Duxbury J M, Virmani S $\mathrm{M}$, et al. Legumes in rice and wheat cropping systems of the Indo-Gangetic Plain - constraints and opportunities. International Crops Research Institute for the Semi-Arid Tropics. New York: Cornell University Press, 35-70.

Bai Z G, Dent D L, Olsson L, et al. 2008. Proxy global assessment of land degradation. Soil Use and Management, 24(3): 223234.

Bajocco S, de Angelis A, Perini A, et al. 2012. The impact of land use/land cover changes on land degradation dynamics: a Mediterranean case study. Environmental Management, 49(5): 980-989.

Behera M D, Chitale V S, Shaw A, et al. 2012. Wetland monitoring, serving as an index of land use change-a study in Samaspur Wetlands, Uttar Pradesh, India. Journal of the Indian Society of Remote Sensing, 40(2): 287-297.

Behera M D, Patidar N, Chitale V S, et al. 2014. Increase in agricultural patch contiguity over the past three decades in Ganga River Basin, India. Current Science, 107(3): 502-511.

Census India. 2011. The Office of the Registrar General \& Census Commissioner, India Online access. [2016-11-22]. www.censusindia.gov.in.

Dardel C, Kergoat L, Hiernaux P, et al. 2014. Rain-Use-Efficiency: What it tells us about the conflicting Sahel greening and Sahelian paradox. Remote Sensing, 6: 3446-3474.

Dregne H E. 1977. Desertification of arid lands. Economic Geography, 53(4): 322-331.

Dubey S K, Pranuthi G, Tripathi S K. 2012. Relationship between NDVI and rainfall relationship over India. International Journal of Water Resources and Environmental Sciences, 1(4): 102-108.

Eckert S, Hüsler F, Liniger H, et al. 2015. Trend analysis of MODIS NDVI time series for detecting land degradation and regeneration in Mongolia. Journal of Arid Environments, 113: 16-28.

EODC. 2015. ESA Climate Change Initiative Phase II Soil Moisture: Soil Moisture ECV Product User Guide (Ver. 10), D330.

[2016-08-07]. www.esa-sst-cci.org/PUG/documents.

Evans J, Geerken R. 2004. Discrimination between climate and human-induced dryland degradation. Journal of Arid Environments, 57(4): 535-554. 
Fensholt R, Langanke T, Rasmussen K, et al. 2012. Greenness in semi-arid areas across the globe 1981-2007 - an Earth Observing Satellite based analysis of trends and drivers. Remote Sensing of Environment, 121: 144-158.

Gabriels D, Cornelis W M. 2009. Human-induced land degradation. In: Land Use, Land Cover and Soil Sciences - Volume III: Land Use Planning, Encyclopaedia of life support system [2016-06-22]. http://www.eolss.net/sample-chapters/c12/E1-05-0305.pdf.

Gupta R K, Naresh R K, Hobbs P R, et al. 2003. Sustainability of post-green revolution agriculture: the rice-wheat cropping systems of the Indo-Gangetic Plains and China. In: Ladha J K, Hill J E, Duxbury J M, et al., Improving the Productivity and Sustainability of Rice-Wheat Systems: Issues and Impacts. Madison: American Society of Agronomy, Inc., Crop Science Society of America, Inc., Soil Science Society of America, Inc., 1-25.

Gupta A K, Tyagi P, Sehgal V K. 2011. Drought disaster challenges and mitigation in India: strategic appraisal. Current Science, 100(12): 1795-1806.

Helldén U, Tottrup C. 2008. Regional desertification: a global synthesis. Global and Planetary Change, 64(3-4): 169-176.

Helsel D R, Hirsch R M. 2002. Statistical methods in water resources. In: Techniques of Water Resources Investigations of the United States Geological Survey, Book 4, Hydrologic Analysis and Interpretation, Chapter A3. [2002-09-22] https://pubs.usgs.gov/twri/twri4a3/pdf/twri4a3-new.pdf.

Higginbottom T P, Symeonakis E. 2014. Assessing land degradation and desertification using vegetation index data: current frameworks and future directions. Remote Sensing, 6(10): 9552-9575.

Hill J, Stellmes M, Udelhoven T, et al. 2008. Mediterranean desertification and land degradation: mapping related land use change syndromes based on satellite observations. Global and Planetary Change, 64(3-4): 146-157.

Holben B N. 1986. Characteristics of maximum-value composite images from temporal AVHRR data. International Journal of Remote Sensing, 7(11): 1417-1434.

Ibrahim Y Z, Balzter H, Kaduk J, et al. 2015. Land degradation assessment using residual trend analysis of GIMMS NDVI3g, soil moisture and rainfall in Sub-Saharan West Africa from 1982 to 2012. Remote Sensing, 7(5): 5471-5494.

Kumar T L, Rao K K. 2013. Studies on spatial pattern of NDVI over India and its relationship with rainfall, air temperature, soil moisture adequacy and ENSO Geofizika, 30: 1-19. [2016-07-22]. http://hrcaksrcehr/indexphp/.

Lamb D. 2011. Forest and land degradation in the Asia-Pacific region. In: Regreening the Bare Hills. World Forests, Vol. 8. Springer, Dordrecht, 61 .

Le Q B, Nkonya E, Mirzabaev A. 2016. Biomass productivity-based mapping of global land degradation hotspots. In: Nkonya E, Mirzabaev A, von Braun J. Economics of Land Degradation and Improvement - A Global Assessment for Sustainable Development. Cham: Springer, 55-84.

Leemans R, Zuidema G. 1995. Evaluating changes in land cover and their importance for global change. Trends in Ecology \& Evolution, 10(2): 76-81.

Li X B, Li R H, Li G Q, et al. 2016. Human-induced vegetation degradation and response of soil nitrogen storage in typical steppes in Inner Mongolia, China. Journal of Arid Environments, 124: 80-90.

Matin S, Chitale V S, Behera M D, et al. 2012. Fauna data integration and species distribution modelling as two major advantages of geoinformatics-based phytobiodiversity study in today's fast changing climate. Biodiversity and Conservation, 21(5): 12291250.

Matin S, Behera M D. 2017. Alarming rise in aridity in the Ganga river basin, India, in past 3.5 decades. Current Science, 112(2): 229-230.

Mbow C, Brandt M, Ouedraogo I, et al. 2015. What four decades of earth observation tell us about land degradation in the Sahel? Remote Sensing, 7: 4048-4067.

NBSS and LUP (National Bureau of Soil Survey and Land Use Planning). 2005. Annual Report 2005. Nagpur: NBSS and LUP, 2.

Reynolds J F, Smith D M S, Lambin E F, et al. 2007. Global desertification: building a science for dryland development. Science, 316(5826): 847-851.

Shiva V. 1991. The Violence of the Green Revolution: Third World Agriculture, Ecology, and Politics. London: Zed Books, 21. Sklenicka P. 2016. Classification of farmland ownership fragmentation as a cause of land degradation: A review on typology, 
consequences, and remedies. Land Use Policy, 57: 694-701.

Suhag R. 2016. Overview of ground water in India. In: PRS Legislative Research ("PRS") standing committee report on Water Resources examined 10 year report. New Delhi, India. [2017-04-02]. https://www.prsindia.org/theprsblog/status-groundwater-extraction-exceeds-recharge.

Symeonakis E, Calvo-Cases A, Arnau-Rosalen E. 2007. Land use change and land degradation in southeastern Mediterranean Spain. Environmental Management, 40(1): 80-94.

UNCCD. 1994. Elaboration of an international convention to combat desertification in countries experiencing serious drought and/or desertification, particularly in Africa. [2016-07-19]. http://wwwunccdint/convention/menu.php.

Wang J, Rich P M, Price K P. 2003. Temporal responses of NDVI to precipitation and temperature in the central Great Plains, USA. International Journal of Remote Sensing, 24(11): 2345-2364.

Wessels K J, Prince S D, Malherbe J, et al. 2007. Can human-induced land degradation be distinguished from the effects of rainfall variability? A case study in South Africa. Journal of Arid Environments, 68(2): 271-297.

Xu L, Myneni R B, Chapin III, et al. 2013. Temperature and vegetation seasonality diminishment over northern lands. Nature Climate Change, 3(3): 581-586.

Yan K, Park T, Yan G, et al. 2016. Evaluation of MODIS LAI/FPAR product collection 6. Part 1: Consistency and improvements. Remote Sensing, 8(5): 359.

Zhang Y, Xiao X, Wu X, et al. 2017. A global moderate resolution dataset of gross primary production of vegetation for $2000-$ 2016. Scientific Data, 4: 170165. 